\title{
Rice Husk Ash Derived Zeolite Blended with Water Hyacinth Ash for Enhanced Adsorption of Cadmium lons
}

\author{
G.W. MBUGUA ${ }^{1}$, H.M.MBUVI ${ }^{*}$ and J.W. MUTHENGIA² \\ ${ }^{1}$ Department of Chemistry, Kenyatta University, P.O. Box 43844-00100, Nairobi, Kenya. \\ ${ }^{2}$ Department of Chemistry, Embu University College, P.O Box 6-60100,Embu, Kenya.
}

http://dx.doi.org/10.12944/CWE.9.2.08

(Received: Feburary 28, 2014; Accepted: May 23, 2014)

\begin{abstract}
In order to help curtail or imposesustained control to the offensive water hyacinth plant, it is essential to explore ways of generating water remediation materials from it. In the current study, the capacity and efficacy of water hyacinth ash (WHA), its insoluble residue (WHAR) and rice husk ash (RHA) to remove cadmium ions and methylene blue from contaminated water was investigated. Mixtures of the two ashes were used to formulate zeolitic materials by hydrothermal reactions. Material A, ZMA was prepared by using rice husk ash and the soluble portion of WHA while for material B, ZMB a mixture of equal amounts the two ashes including the insoluble fraction of WHA were used. Batch experiments was carried out to determine the effect of metal ion concentration, initial $\mathrm{PH}$, contact time (t), temperature $(\mathrm{T})$, shaking speed and adsorbent dose on percentage removal of $\mathrm{Cd}^{2+}$ and methylene blue by the ashes and their zeolitic products. The data obtained for adsorption of $\mathrm{Cd}^{2+}$ on RHA, ZMA, and ZMB was found to best fit in the Langmuir isotherm model while WHA and WHAR data best fitted in the Freundlich model. Adsorption capacities for cadmium on RHA, WHA, WHAR, ZMA and ZMB adsorbents ions were 3.745, 52.00, 56.89, 11.24 and $22.22 \mathrm{mg} / \mathrm{g}$ respectively. The findings showed that incorporating the WHAR during synthesis of the zeolitic material enhanced its adsorption capacity and efficiency for $\mathrm{Cd}$ (II) ions and methylene blue.
\end{abstract}

Key words: Adsorption isotherms, Heavy metals, Zeolite, Water remediation, Adsorbents.

\section{INTRODUCTION}

17.2 million People in Kenya who constitute about 43 percent of the population have no access clean water. The major factors contributing to this water crisis include rapid population growth, droughts, forest degradation, poor management of water supply and water contamination. This water crisis may worsen as industrial development and population grows as projected if drastic measures are not taken immediately. The water hyacinth menace has further complicated the issue by not only contaminating our water bodies but also rendering many Kenya lakes idle with minimal economic activities taking place. The rapid population growth both in rural and urban areas has stressed the existing water supply systems ${ }^{1}$. This accompanied by unsuitable water supply infrastructure has hindered access to water by the poor in many developing countries $^{2}$. There has been remarkable growth in light and informal (jua kali) industries like textiles, leather, paper, plastics, electroplating, cement, metal processing, wood preservatives, paints, pigments and steel fabricating industries ${ }^{3}$. These industries discharge large quantities of toxic wastes ${ }^{4}$. Recent studies in Kenya have reported that the open-air mechanical workshops are significant sources of mobile and bioavailable heavy metal contaminants ${ }^{1,2}$. Several processes exist for removing dissolved heavy metals, including ion exchange, precipitation, ultrafiltration, reverse osmosis, electrodialysis and adsorption ${ }^{3}$. Many of these approaches demand high energy, advanced operational requirement or difficult to treat and do not enable recovery of metals 
or material. It is therefore most desirable to explore possibilities of developing cheap water treatment materials and curbing or putting water hyacinth under maintained control in tandem. The findings herein suggest that rice husk and water hyacinth can be used as raw materials for synthesizing adsorbent materials for heavy metal removal from contaminated water.

\section{MATERIALS AND METHODS}

\section{Chemicals}

A stock solution of cadmium with a concentration of $1000 \mathrm{mg} / \mathrm{L}$ was prepared by dissolving $2.745 \mathrm{~g}$ of cadmium nitrate in $1000 \mathrm{~mL}$ distilled water in volumetric flask. The solution was then diluted to obtain standard solutions containing $0.1,0.2,0.4,0.8,1.6$ and $3.2 \mathrm{ppm}$. Concentrated Nitric acid and sodium hydroxide solutions were used throughout experiments to adjust the $\mathrm{pH}$ of the solution.

Rice husk ash, water hyacinth ash and water hyacinth ash residue preparation

Water hyacinth plants were obtained from Nairobi dam. They were then transported to the laboratory where they were extensively washed with tap water to remove soil and dust, sliced into pieces and then air dried for one week using a procedure already documented by ${ }^{4}$. Ashing was done using an oven at a temperature of $950^{\circ}$ for five hours. The ash was mixed to obtain a composite sample. Samples were sieved to obtain particles of the same size. Fig I shows a sample of water hyacinth ash, WHA. Water hyacinth ash residue (WHAR) was prepared by dissolving $50 \mathrm{~g}$ of water hyacinth ash in 250 $\mathrm{cm}^{3}$ of distilled water. The mixture was shaken for five minutes and allowed to settle. Filtration was done using whatsman No. filter paper. The residue was then sun dried for five hours. Rice husks were provided by Euros rice millers in Kirinyaga County, Mwea west district. They were then washed several times with distilled water to remove soil and dust, followed by filtration and then dried at $100^{\circ}$. The clean and dry rice husks were burnt in an oven at $500^{\circ}$ for $3 \mathrm{hrs}$ to obtain ash. Figure II shows a picture of a sample of rice husk ash, RHA.

\section{Potassium hydroxide solution}

$1 \mathrm{M}$ potassium hydroxide was generated from water hyacinth ash by dissolving $50 \mathrm{~g}$ of WHA and filtering off the residue. Titration experiments were done to determine the concentration of the alkaline solution using $0.1 \mathrm{M}$ hydrochloric acid.

\section{Synthesis of zeolitic material, ZMA}

$25 \mathrm{~g}$ of rice husk ash was conditioned into three stainless steel digestion bomb. $250 \mathrm{~mL}$ of potassium hydroxide solution was added on this ash; the bomb was closed and introduced into a pre-heated oven at $200^{\circ} \mathrm{C}$ for a period of $24 \mathrm{hrs}$. The contents were then allowed to cool and filtered. The solid residue was washed with distilled water to remove the excess alkali and dried at $105^{\circ} \mathrm{C}$ for $12 \mathrm{hrs}$. The solid residue was designated as ZMA and is shown in Fig 3.

\section{Preparation of zeolitic material B, ZMB}

For the preparation of $Z M B, 50 \mathrm{~g}$ of rice husk ash and $50 \mathrm{~g}$ of water hyacinth ash were put in a reaction bomb. $250 \mathrm{~mL}$ of distilled water was added to the mixture. The bomb was put in a preheated oven at $200^{\circ} \mathrm{C}$ for $12 \mathrm{hrs}$. The formed solid was washed with hot distilled water to remove the excess alkali. It was then dried at $105^{\circ} \mathrm{C}$ for $12 \mathrm{hrs}$. The samples were designated as ZMB and shown in fig 4.

\section{Preparation of standard and test solution of $\mathrm{Cd}^{2+}$}

A known mass, $2.745 \mathrm{~g}$ of analytical grade cadmium nitrate $\left.\mathrm{Cd}\left(\mathrm{NO}_{3}\right)_{2}\right)$ was dissolved in $200 \mathrm{~mL}$ of distilled water. The resulting solution was diluted to $1000 \mathrm{~mL}$ mark using distilled water. This was the $1000 \mathrm{ppm}$ stock solutionof cadmium. Standard solutions were prepared by successive dilution of the stock solution.

\section{Instrumentation}

The $\mathrm{Cd}^{2+}$ ion concentrations in the various solutions were determined using atomic absorption spectrophotometer model AAS 4141, ECIL, India at wave length $283.3 \mathrm{~nm}$ in flame mode using airacetylene flame. The $\mathrm{pH}$ meter, model PHEP, Hanna instrument, Italy, was used in this study between $\mathrm{pH}$ ranges $2-12$ at a temperature of $22.7^{\circ} \mathrm{C}$ and UV-visible spectrometer. The concentrations were determined in triplicates. A standard and blank sample was run after every seven samples to check instrumental drift. Calibration curve method was used to quantify the heavy metal concentration. 


\section{Batch experiments}

A temperature-controlled water-bath shaker (DKZ-1 NO.1007827) was used for the batch adsorption experiments. The experiments were performed at the same shaking speed. For each experimental run, $50 \mathrm{~mL}$ aqueous solution of known concentrations of $\mathrm{Cd}^{2+}$ ion were put in $120 \mathrm{~mL}$ plastic bottles that contained known masses of RHA, ZMA, ZMB, WHA and WHAR. These bottles were agitated at a constant shaking rate of $150 \mathrm{rpm}$ and temperature of $25^{\circ} \mathrm{C}$, centrifuged and filtered. The concentration of $\mathrm{Cd}^{2+}$ ions in the filtrates obtained were measured using flame atomic adsorption spectrometry. Amount of $\mathrm{Cd}^{2+}$ ions adsorbed per unit mass of adsorbed and the percentage of $\mathrm{Cd}^{2+}$ ions removed were calculated using the equations 1 and 2 respectively

$$
\begin{aligned}
& \mathrm{qe}=\frac{(C o-C e)}{m} V \\
& \mathrm{R}=100 \frac{C o-C e}{C o}
\end{aligned}
$$

Where,

$\mathrm{qe}=$ Amount of $\mathrm{Cd}^{2+}$ ions adsorbed per unit mass of adsorbed at equilibrium.

Co $=$ Initial concentration of sorbate.

$\mathrm{Ce}=$ Concentration of sorbate at equilibrium.

$\mathrm{m}=$ mass of sorbate (atomic mass).

$\mathrm{V}=$ volume of solution,

Effect of the various parameters on the percentage of $\mathbf{C d}^{2+}$ ions adsorbed

The effects of various parameters (adsorbent dose, contact time, initial concentrations, $\mathrm{pH}$ and temperature) on the percentage of $\mathrm{Cd}^{2+}$ ions adsorbed were investigated by varying the parameter of interest while keeping all the others constant. The effect of initial concentration was investigated by varying initial concentration from 10 to $500 \mathrm{ppm}$ at same conditions of: $0.1 \mathrm{~g}$ of adsorbents, temperature of $25^{\circ} \mathrm{C}$, agitation speed of speed of $150 \mathrm{rpm}, \mathrm{pH} 5$, and contact time of $24 \mathrm{hrs}$. The effect of the adsorbent dosage was investigated by varying the doses from 0.02 to $2.5 \mathrm{~g}$ at same conditions of: $10 \mathrm{ppm} \mathrm{Cd}^{2}$ ion solutions for WHA, RHA and ZMA and 100 ppm for WHAR and ZMB, pH 5, agitation speed of speed of $150 \mathrm{rpm}$, temperature of $25^{\circ}$ and contact time of $2 \mathrm{hrs}$. The effect of contact time was investigated by varying contact time from 1 to $14400 \mathrm{~min}$ at same conditions of: $0.1 \mathrm{~g}$ of adsorbents, $10 \mathrm{ppm} \mathrm{Cd}^{2+}$ ion solutions for WHA, RHA and ZMA and 100ppm for WHAR and ZMB, temperature of $25^{\circ} \mathrm{C}$, agitation speed of speed of $150 \mathrm{rpm}, \mathrm{pH}$ 5. The effect of $\mathrm{pH}$ was investigated by varying $\mathrm{pH}$ from 2 to 12 at same conditions of: $0.1 \mathrm{~g}$ of adsorbents, $10 \mathrm{ppm} \mathrm{Cd}^{2+}$ ion solutions for WHA, RHA and ZMA and 100 ppm for WHAR and ZMB, temperature of $25^{\circ} \mathrm{C}$, agitation speed of speed of $150 \mathrm{rpm}$, contact time $2 \mathrm{hrs}$.

\section{Removal of methylene blue dye from water}

A stock solution of methylene blue of concentration 1000 ppm was prepared by dissolving $1 \mathrm{~g}$ of methylene blue in a $100 \mathrm{ml}$ volumentric flask using distilled water. The solution was shaken to obtain homogeneity. Solutions of various concentrations were obtained by dilution. The effect of the amount of methylene blue adsorbed was studied by agitating different concentrations of 50 $\mathrm{ml}$ of coloured water with $0.1,0.2,0.3,0.4$, and $0.5 \mathrm{~g}$ of WHA, WHAR, RHA, ZMA and ZMB for two hours. The solution was then filtered using whatman No. 1 filter paper and the colour in water was determined using UV Spectrophotometer. All these studies were conducted at $25^{\circ} \mathrm{C}$ and agitation speed of 150rpm.

\section{RESULTS AND DISCUSSIONS}

\section{Samples characterization}

The chemical compositions of RHA, WHA, WHAR, ZMA, and ZMB were determined by XRF and are shown in tables 1, 2, 3, 4 and 5 respectively. As shown in table $1, \mathrm{RHA}$ is a good source of $\mathrm{SiO}_{2}$ and $\mathrm{Al}_{2} \mathrm{O}_{3}$ as it contained $77 \%$ and $12 \%$ respectively. WHA had $35.8 \%$ of $\mathrm{K}_{2} \mathrm{O}$ followed by $27 \%$ of $\mathrm{CaO}$ and $\mathrm{Cl}$ at $21 \%$ hence serving as a good source of $\mathrm{KOH}$ base.

\section{Effect of theinitial concentrations of $\mathrm{Cd}^{2+}$ ions}

The percentage of $\mathrm{Cd}^{2+}$ ions adsorbed by ZMA, ZMB, WHA, RHA and WHAR was significantly influenced by the initial concentration of $\mathrm{Cd}^{2+}$ ions in aqueous solutions. The initial $\mathrm{Cd}^{2+}$ concentration was varied from $10 \mathrm{ppm}$ to $500 \mathrm{ppm}$ while maintaining the adsorbent dosage at $0.1 \mathrm{~g}$. Figure 5 shows the effect of initial concentration on percentage removal of $\mathrm{Cd}^{2+}$ ions. The percentage removal of $\mathrm{Cd}^{2+}$ increased from $86.2 \%$ to $99.75 \%$ for $\mathrm{RHA}, 85.45 \%$ to $99.93 \%$ for ZMA, $99.0 \%$ to $98.1 \%$ WHAR, $50.5 \%$ to $99.5 \%$ 
for WHA and $97.8 \%$ to $99.4 \%$ for ZMB at the same contact time and adsorption temperature. Further increase in concentration lead to a decrease in percentage removal of cadmium ions due to an increase in the number of $\mathrm{Cd}^{2+}$ ions for the fixed amount of adsorbent.

Effects of temperature on the adsorption of cadmium ions

The effect of temperature on the removal of $\mathrm{Cd}^{2+}$ ions by WHA, RHA, WHAR, ZMA and ZMB at initial solution concentration of $10 \mathrm{ppm}$ for RHA, WHA and ZMA and 100ppm for WHAR and ZMB, using $0.1 \mathrm{~g}$ and contact time of $120 \mathrm{~min}$ and agitation speed of 150rpm are shown in figure 6. From the results, it was observed that the percentage removal

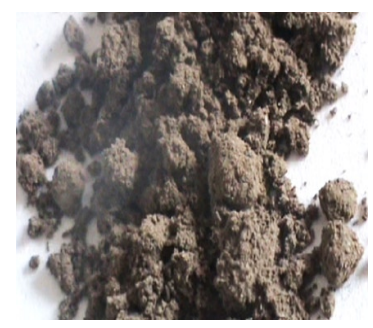

Fig. 1: High resolution picture of a sample of water hyacinth ash, WHA

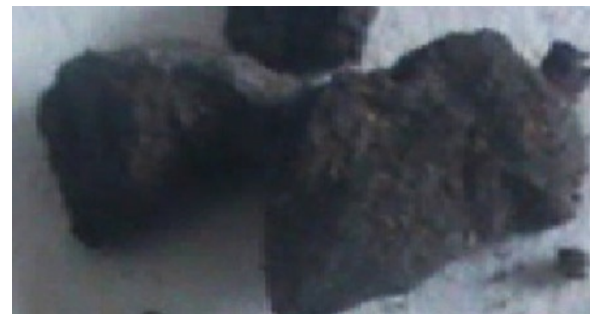

Fig. 3: High resolution picture of zeolitic material A, ZMA of cadmium ions by WHA, WHAR and ZMB remained constant with increase in temperature. There was a rapid decrease in percentage removal of cadmium ion by RHA and ZMA when the temperature was increased from $298 \mathrm{k}$ to $374 \mathrm{k}$. The observed initial decrease in cadmium removal with increasing temperature suggests weak binding interaction between the active sites and cadmium ions which support physisorption which are exothermic and therefore favoured by low temperature ${ }^{1}$.

\section{Effect of adsorbent dosage on adsorption of Cadmium ions}

Experiments were conducted with the adsorbent dose of $0.02,0.04,0.06,0.1,0.2,0.3$ $0.4,0.5,1.0,1.5,2.0$ and $2.5 \mathrm{~g}$ per $50 \mathrm{~mL}$ of test

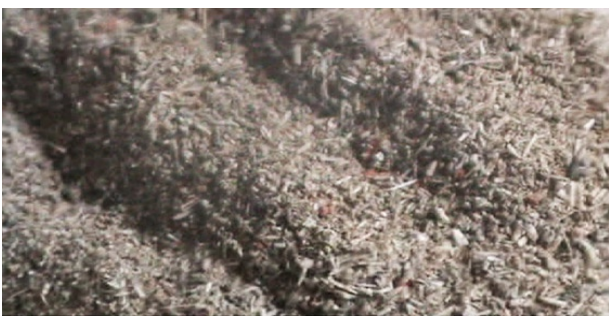

Fig. 2: High resolution picture of a sample of rice husk ash, RHA

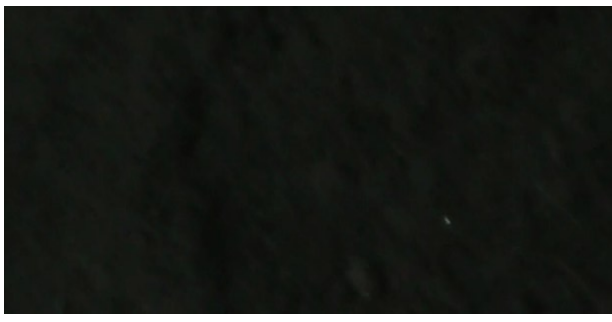

Fig. 4: High resolution picture of zeolitic material B, ZMB

Table 1: XRF analysis for Rice husk ash, RHA

\begin{tabular}{cccccccc}
\hline Compound & $\mathrm{Al}_{2} \mathrm{O}_{3}$ & $\mathrm{SiO}_{2}$ & $\mathrm{~K}_{2} \mathrm{O}$ & $\mathrm{CaO}$ & $\mathrm{TiO}_{2}$ & $\mathrm{MnO}$ & $\mathrm{Fe}_{2} \mathrm{O}_{3}$ \\
\hline$\%$ oxide & $12 \%$ & $77 \%$ & $1.5 \%$ & $1.3 \%$ & $0.97 \%$ & $0.21 \%$ & $7.21 \%$ \\
\hline
\end{tabular}

Table 2: XRF analysis for Water hyacinth ash, WHA

\begin{tabular}{ccccccccc}
\hline Compound & $\mathrm{Al}_{2} \mathrm{O}_{3}$ & $\mathrm{P}_{2} \mathrm{O}_{5}$ & $\mathrm{Cl}$ & $\mathrm{K}_{2} \mathrm{O}$ & $\mathrm{CaO}$ & $\mathrm{MnO}$ & $\mathrm{Fe}_{2} \mathrm{O}_{3}$ & $\mathrm{ZnO}$ \\
\hline$\%$ oxide & $1 \%$ & $6.0 \%$ & $21 \%$ & $35.8 \%$ & $27 \%$ & $7.1 \%$ & $1.8 \%$ & $0.2 \%$ \\
\hline
\end{tabular}


solution. When the addition of the adsorbent dose increased, the percentage removal of metal ions also increased as shown in fig 7. Adsorption of cadmium ions increased due to increase in number of binding sites as the adsorbent dose increased. A maximum removal of $99.99 \%$ at $2.0 \mathrm{~g} Z \mathrm{ZMA}, 99.40 \%$ at $2.5 \mathrm{~g} \mathrm{RHA}, 99.12 \%$ at $0.1 \mathrm{~g} \mathrm{ZMB}, 100 \%$ at $1.5 \mathrm{~g}$ WHA and WHAR was observed. A further increase in adsorbent dose did not have any significant effect on the removal of cadmium ions from the solution.

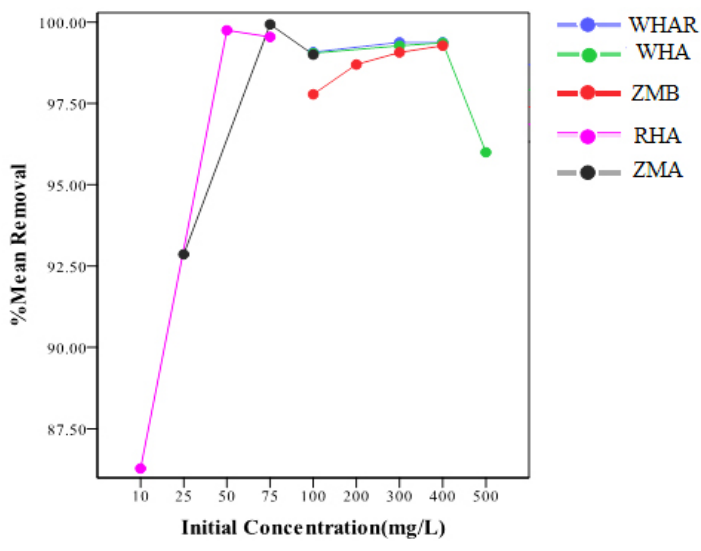

Fig. 5: percentage of $\mathrm{Cd} 2+$ ions adsorbed at saturation using $0.1 \mathrm{~g}$ of WHA, WHAR, RHA, ZMA and ZMB at various initial concentrations (amount of biosorbent $=0.1 \mathrm{~g}$, contact time = 24 hours and agitation speed = 150rpm)

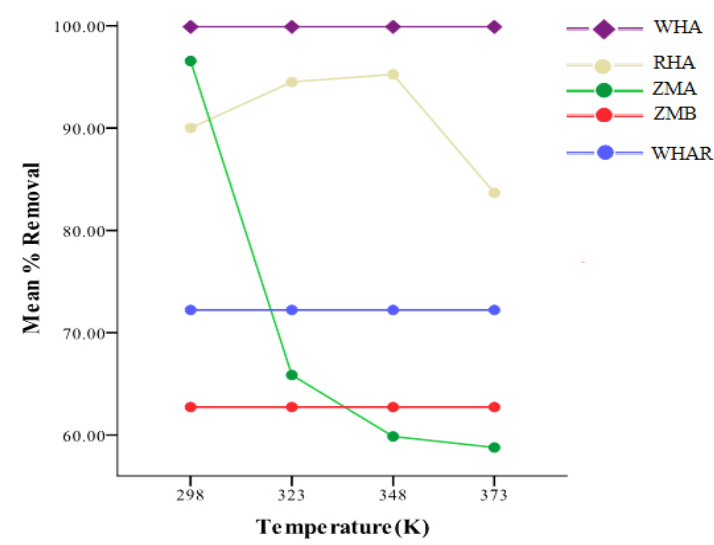

Fig. 6: Effect of temperature on the removal of Cd2+ ions by WHA, RHA, WHAR, ZMA and ZMB (initial solution concentration $=10 \mathrm{ppm}$ for RHA, WHA and ZMA and 100ppm for WHAR and $Z M B$, amount of biosorbent $=\mathbf{0 . 1 \mathrm { g } \text { and }}$ contact time $=120 \mathrm{~min}$ agitation speed $=$ 150rpm)
Effect of contact time on percentage removal of cadmium ion

Experiments were conducted by, varying contact time from 1 to 1440 min while maintaining all other experimental conditions constant. The results obtained are shown in Fig. 8. As shown the adsorption process occurred rapidly when WHA, WHAR and ZMB were used with almost $100 \%$ of the cadmium present adsorbed after $1 \mathrm{~min}$. There was an overlap between ZMB and WHA. ZMA achieved $66 \%$ removal after $30 \mathrm{~min}, 95 \%$ after 90 min and reached equilibrium within 2 hrs while $\mathrm{RHA}$ achieved $72 \%$ removal by $30 \mathrm{~min}, 99 \%$ by $90 \mathrm{~min}$ and reachedequilibrium within $2 \mathrm{hrs}$. This suggests that the bonding of the cadmium ion to active sites occurs preferably on the solid surface ${ }^{1}$.

\section{Effects of PH on percentage removal of cadmium ion}

The effect of $\mathrm{pH}$ on the removal efficiency of cadmium ions is studied from $\mathrm{pH} 2$ to 12 . The percentage removal was found to be $99.73 \%$ for $\mathrm{RHA}$ at $\mathrm{pH} 4,99.32 \%$ for $\mathrm{ZMA}$ at $\mathrm{PH} 9,99.7 \%$ for water hyacinth ash at $\mathrm{PH} 9,99.12 \%$ for WHA and $\mathrm{ZMB}$ at $\mathrm{PH} 7$ and 9 as shown in Figure 9. At low $\mathrm{pH}$, carboxylic and amino functional groups of adsorbents are protonated ${ }^{2}$, thus active sites are less available for metal ion binding and thus cadmium ions were less absorbed. Thereafter, the percentage

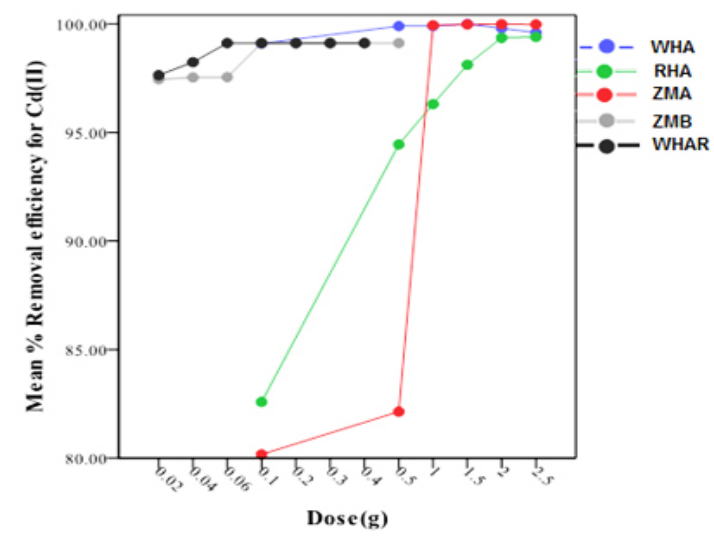

Fig. 7: Effect of adsorbed doses on the percentage removal of $\mathrm{Cd}^{2+}$ ions by WHA, RHA, WHAR, ZMA and ZMB (initial solution concentration = 10 ppm for RHA, WHA and ZMA and 100ppm for WHAR and ZMB, contact time $=120 \mathrm{~min}$ agitation speed $=150 \mathrm{rpm}, \mathrm{pH}=5$ 


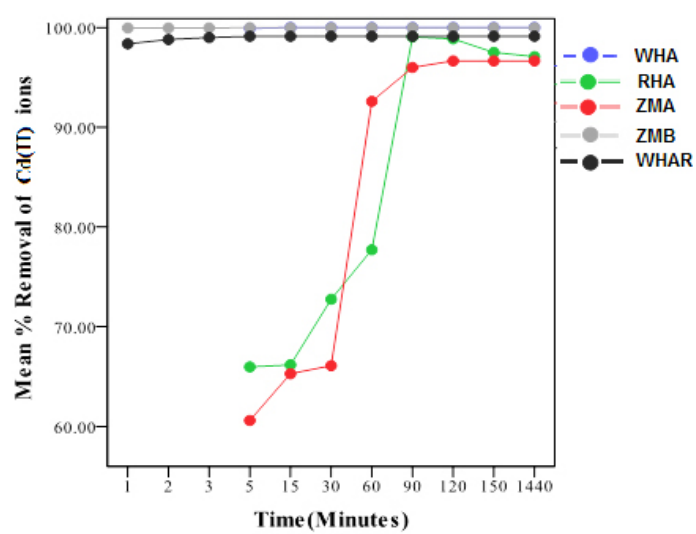

Fig. 8: Effect of contact time on the percentage removal of $\mathrm{Cd}^{2+}$ ions by WHA, RHA, WHAR, ZMA and ZMB (initial solution concentration = 10 ppm for RHA, WHA and ZMA and 100ppm

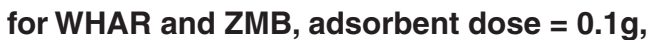
agitation speed $=150 \mathrm{rpm}, \mathrm{pH}=5$

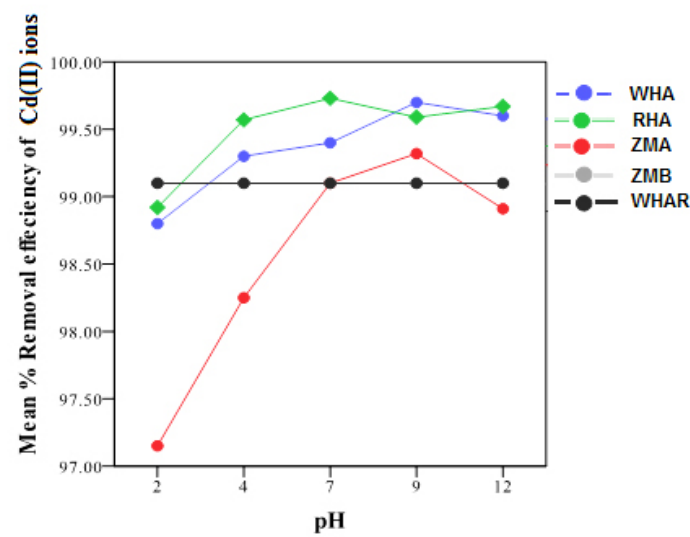

Fig. 9: Effect of contact time on the percentage removal of $\mathrm{Cd}^{2+}$ ions by WHA, RHA, WHAR, ZMA and ZMB (initial solution concentration = 10 ppm for RHA, WHA and ZMA and 100ppm for WHAR and ZMB, adsorbent dose $=0.1 \mathrm{~g}$, agitation speed $=150 \mathrm{rpm}$, contact time $=2 \mathrm{hrs}$

Table 3:XRF analysis for Water hyacinth ash residual, WHAR

\begin{tabular}{lcccccc}
\hline Compound & $\mathrm{Al}_{2} \mathbf{O}_{3}$ & $\mathbf{P}_{2} \mathbf{O}_{5}$ & $\mathbf{K}_{2} \mathbf{O}$ & $\mathrm{CaO}$ & $\mathrm{MnO}$ & $\mathrm{Fe}_{2} \mathbf{O}_{3}$ \\
\hline$\%$ oxide & $4 \%$ & $9.9 \%$ & $9.9 \%$ & $54.8 \%$ & $15.9 \%$ & $5.9 \%$ \\
\hline
\end{tabular}

Table 4: XRF analysis for Zeolitic material A, ZMA

\begin{tabular}{llllllll}
\hline Compound & $\mathrm{Al}_{2} \mathrm{O}_{3}$ & $\mathrm{SiO}_{2}$ & $\mathrm{~K}_{2} \mathrm{O}$ & $\mathrm{CaO}$ & $\mathrm{TiO}_{2}$ & $\mathrm{MnO}$ & $\mathrm{Fe}_{2} \mathrm{O}_{3}$ \\
\hline$\%$ oxide & $7.8 \%$ & $75 \%$ & $3.3 \%$ & $1.1 \%$ & $1.3 \%$ & $0.45 \%$ & $10.45 \%$ \\
\hline
\end{tabular}

Table 5: XRF analysis for Zeolitic material B, ZMB

\begin{tabular}{lcccccccc}
\hline Compound & $\mathrm{Al}_{2} \mathrm{O}_{3}$ & $\mathrm{SiO}_{2}$ & $\mathrm{~K}_{2} \mathrm{O}$ & $\mathrm{CaO}$ & $\mathrm{TiO}_{2}$ & $\mathrm{MnO}$ & $\mathrm{Fe}_{2} \mathrm{O}_{3}$ & $\mathbf{P}_{2} \mathbf{O}_{5}$ \\
\hline$\%$ oxide & $10.52 \%$ & $76.22 \%$ & $2.7 \%$ & $1.76 \%$ & $0.04 \%$ & $2.08 \%$ & $2.01 \%$ & $4.63 \%$ \\
\hline
\end{tabular}

Table 6: Langmuir and Freundlich isotherm constants for cadmium

\begin{tabular}{|c|c|c|c|c|c|c|}
\hline \multirow[b]{2}{*}{ sample } & \multicolumn{3}{|c|}{ Langmuir } & \multicolumn{3}{|c|}{ Freundlich } \\
\hline & $q_{\max } m g / g$ & b dm³/g & $\mathbf{R}^{2}$ & $1 / n$ & $\mathrm{~K}_{\mathrm{f}} \mathrm{mg} / \mathrm{g}$ & $\mathbf{R}^{2}$ \\
\hline $\mathrm{RHA}$ & 3.745 & 5.03 & 0.999 & 0.785 & 7.59 & 0.674 \\
\hline WHA & 200 & 0.208 & 0.934 & 1.43 & 52.00 & 0.979 \\
\hline WHAR & 250 & 0.018 & 0.842 & 1.486 & 56.89 & 0.992 \\
\hline ZMA & 11.24 & 22.25 & 1 & 0.385 & 15 & 0.908 \\
\hline ZMB & 22.22 & 0.303 & 0.998 & 5.103 & 5.103 & 0.987 \\
\hline
\end{tabular}


removal of cadmium ions decreased with increase in $\mathrm{PH}$. This is as a result of increase in $\mathrm{OH}^{\prime \prime}$ ions cause a decrease in adsorption of metal ions at adsorbent adsorbate interface ${ }^{33}$

\section{Langmuir and Freundlich isotherm constants for cadmium}

As shown in Table 6, adsorption data for WHA and WHAR best fitted inFreundlich model with $\mathrm{R}^{2}=0.979$ and 0.992 respectively while $\mathrm{RHA} Z \mathrm{ZMA}$ and $Z M B$ best fitted to the Langmuir model with $\mathrm{R}^{2}$ $=0.999,1$ and 0.998. WHAR and WHA had the highest affinity for $\mathrm{Cd}^{2+}$ ions with adsorption capacity of 56.89 and $52.00 \mathrm{mg} / \mathrm{g}$ respectively. They also had $\mathrm{a} 1 / \mathrm{n}$ value greater than one indicating the adsorption process was favourable in Freundlich isotherm model. ZMA and ZMB had adsorption capacity of 11.24 and $22.22 \mathrm{mg} / \mathrm{g}$ respectively indicating that incoperating the insoluble WHAR in the zeolitic synthesis enhances the materials adsorption for $\mathrm{Cd}^{2+}$ ions. The study showed that ZMA, ZMB, WHA, WHAR and RHA could effectively remove cadmium ions and that adsorption was enhanced in WHAR blended ZMB

\section{ACKNOWLEDGEMENT}

We are grateful to Kenyatta University and Chemistry Department for supporting our project

\section{REFERENCES}

1. Green, P.,Vorosmarty, C., Salisbury, J., Lammers R. Global water resources: Vulnerability from climate change and population growth.Science, 5477, 284 (2000).

2. Cline, S., Rosegrant, M., Cai X. Global water outlook to 2025. International Food Policy Research Institute (2002).

3. Chen, C., Dong, C., Kao, C. Distribution and accumulation of heavy metals in the sediments of Kaohsiung Harbor, Taiwan. Chemosphere, (8), 1431-1440 (2007).

4. Cheng, S. Heavy metal pollution in China: origin, pattern and control. Environmental Science and Pollution Research, (3), 192198 (2003).

5. Chengo K., Murungi J., Mbuvi H.M. Speciation of Zinc and Copper in Open-Air Automobile Mechanic Workshop Soils in Ngara AreaNairobi Kenya, Resources and Environment, (3), 145-154 (2013).

6. Chengo K., Murungi J., Mbuvi H.M. Speciation of Chromium and Nickel in Open-Air Automobile Mechanic Workshop Soils in Ngara Area-Nairobi Kenya, World Environment, (3), 143-154 (2013).

7. Burton, F. and Tchobanoglous, G. wastewater engineering treatment, disposal and reuse
(Metcalf and Eddy, Inc,). McGraw-Hill, NewYork (1991).

8. Kruatrachue, M., Lu, X., Pokethitiyook, P., Homyok, K. Removal of cadmium and zinc by water hyacinth, Eichhorniacrassipes.Science Asia, 30, 93-103 (2004).

9. Mataka LM, Salidu SM, Masamba WRL, Mwatseteza JF. Cadmium sorption by Moingastenopetala and Moringaoleiferaseed powder. Int. J. Environ. Sci. Techno/3(2):131139 (2010).

10. Blazquez, G. Hernainz, F. Calero, M. RuizNuìnPez, L.F. Removal of cadmium ions with olive stones: the effect of some parameters, Process Biochemistry, 40: 2649-2654 (2005).

11. Krishnan, K. A., and Anirudhan, T. S. Removal of cadmium (II) from aqueous solutions by steam-activated sulphurised carbon prepared from sugar-cane bagasse pith: Kinetics and equilibrium studies. Water Sa, 29(2), 147-156 (2003).

12. Periasamy, K., \&Namasivayam, C. Removal of nickel (II) from aqueous solution and nickel plating industry wastewater using an agricultural waste: peanut hulls. Waste management, 15(1), 63-68 (1995). 